\title{
HEGEL Y EL ALMA BELLA. CONSIDERACIONES ÉTICO- POLÍTICAS DESDE LA FENOMENOLOGÍA DEL ESPÍRITU
}

\author{
Francisco Vega C. ${ }^{1}$ \\ Pontificia Universidad Católica de Valparaíso.
}

Resumen: En este trabajo se intentará abordar la problemática que, tras un repaso históricosistemático, gobierna el horizonte interpretativo de la filosofía hegeliana en torno a los movimientos ilustrados. Se trata de la fundación de una nueva cultura nacional y el establecimiento de una verdadera efectividad política del pensamiento. Para ello, yuxtapondré algunos textos hegelianos y daré una articulación final comentando ciertos pasajes de la Fenomenología del espíritu en su relación tácita con otras tentativas de resolución política. Trataré específicamente el problema de la interpretación hegeliana de la llustración y el alma bella.

Palabras clave: Ilustración, Romanticismo, política, buena conciencia, alma bella

\section{Hegel and the beautiful soul. Ethical a nd political considerations from the Phenomenology of Spirit}

\begin{abstract}
This paper will attempt to address the problem that (after a systematic historical review) governs the interpretive horizon of Hegel's philosophy about the movements illustrated. This is the foundation of a new national culture and the establishment of a real political effectiveness of thought. To do this, we juxtapose some Hegelian texts and compare final passages of the Phenomenology of spirit in with other attempts of tacit political resolution. We will analyze specifically the problem of Hegel's interpretation of the Enlightenment and the beautiful soul.
\end{abstract}

Keywords: Enlightenment, Romanticism, politics, good conscience, beautiful soul

\section{Introducción: El mosaico de la llustración.}

Si quisiéramos destacar ciertos aspectos relevantes para elaborar un friso adecuado a la clausura epocal que el pensamiento hegeliano desde temprano empieza a problematizar, tendríamos que procesar a lo menos de forma detallada cuales serían los rasgos de la crítica romántica como del clasicismo a la normatividad ilustrada. Cabe destacar a este respecto que de la Aufklärung se desprenderían estas corrientes en el intento de superar la decadencia de la ilustración berlinesa queriendo refundar míticamente la constitución de la nación alemana que, tras la Paz de Vestfalia, parecía ya condenada. Es el statu quo del Berlín ilustrado de Federico Guillermo II el que movilizará críticamente romanticismo y clasicismo en ese intento de superar la aporeticidad de la Alemania decadente ${ }^{2}$.

Para aquellos que quieran hacer de la primera tentativa hegeliana, fervorosa de la revolución, una suerte de irracionalismo panlogicista, sirva de ejemplo el hecho de que en Hegel no es el racionalismo ilustrado berlinés el que soporta

\footnotetext{
${ }^{1}$ Magíster (C en Filosofía, Pontificia Universidad Católica de Valparaíso.

2 Para un detallado panorama de este mosaico de dispositivos políticos (poesía, música, filosofía) veáse el libro de J. M. Ripalda que aportará el eje de este marco introductorio: Fin del clasicismo. A vueltas con Hegel, Madrid, Trotta, 1992.
} 
los motivos críticos de la época, sino, por una parte, la mediocridad imperante que no hallaba camino entre la masa supersticiosa y la política del momento, como, por otra, su doctrina de la inmediatez y su oposición a lo infinito que, en Hegel, adoptará, por lo menos, algunos motivos fundamentales de discordia con los amigos de Tubinga en torno a ese "seco entendimiento de lo finito".

Y es que, en el intento de salida de ese statu quo ilustrado, parecía colocarse como égida de emancipación una cuádruple articulación. Por una parte, en filosofía, el idealismo fichteano como superación de las aporías dejadas por el criticismo kantiano. Por otra parte, en política, el reconocimiento crítico del cuerpo jurídico imperante como máquina de abstracción y el reconocimiento positivo de la constitución como manifestación histórica de un pueblo. Además, el establecimiento del genio y la fantasía en el campo estético. Finalmente, en religión, el reconocimiento de la historia múltiple de la mitología. Hegel, a este respecto, aduce razones, en sus Escritos juveniles, para plegarse a este movimiento que puede entenderse ya como una llustración de la llustración. Pero, en el punto específicamente filosófico, debería considerarse seriamente el silencio de Hegel, en la correspondencia con Hölderlin y Schelling, respecto al estatuto del Idealismo trascendental y su propagación académica ${ }^{3}$. Tal silencio, sus reticencias a plegarse a la filosofía especulativa en ciernes, podría entenderse como un gesto filosófico en sí mismo que detonará posteriormente en 1807 con la aparición de la Fenomenología del espíritu.

\section{El silencio de Hegel}

"Es cierto que el espíritu con la naturaleza debe unirse Pero no demasiado deprisa ni cuando aún es profano; Así separa a quienes piensan que ya están unidos..."4

El intento de buscar un primer fundamento al saber, lo no-cosa, lo incondicionado, mostraría en el pensamiento fichteano, tras el intento de superar definitivamente la escisión kantiana entre libertad y naturaleza, que éste, el principio incondicionado, se halla en el mismo pensamiento que lo piensa, esto es, el yo trascendental, que revela, a través del "yo soy" la identidad cabal revelada en la intuición pura. De tal forma el yo y su resistencia, no-yo, se darían en esa identidad, de la cual dimana al fin la libertad absoluta o racionalidad práctica. Como se hace notorio, el hilo conductor del problema de la libertad que se nos plantea se deduce de la problemática de la identidad. Habría en Fichte una unidad indiferenciada revelada por la intuición en la que se manifiesta la libertad. De ahí que señale que lo primero para el idealista es la libertad y que el ser es la mera negación de lo primero. Libertad entonces como consciencia inmediata del pensar, intuida. Para Hegel se trataría de una libertad an sich en cuanto la razón afirmada en su autonomía se afirma por una escisión externa, desde el sujeto de la autoposición, que suprime la interna referencia de esa afirmación al polo de la aparición, el no-yo.

\footnotetext{
${ }^{3}$ Cfr. J. M. Ripalda, op. cit., pp. 126-127.

${ }^{4}$ G. W. F. HEGEL, Escritos de juventud. Trad. J. M. Ripalda, Z. Szankay, Madrid: FCE, 1978, p. 95.
} 
Pues bien, Schelling, tempranamente y contra de lo que comúnmente se piensa, reconocería que la escisión en la doctrina de Fichte no está bien superada y que, por tanto, el fundamento de la libertad sigue siendo negado. Con Spinoza, planteará Schelling la identidad absoluta, donde lo subjetivo y lo objetivo dimanan del mismo fundamento superior. La diferencia surge en este esquema por la escisión de la propia razón (rasgo de enajenación reconocido por Hegel en su oposición a Fichte ${ }^{5}$ ). Lo interesante es que Schelling reprochará el reconocimiento a-crítico de la oposición al yo en Fichte pero para volver a colocar, ahora por encima de la relación de oposición, una identidad o unidad indiferenciada, lo verdaderamente absoluto una vez asumida correctamente la oposición al yo, por lo menos hasta el Sistema del idealismo trascendental cuando menciona en busca de una fundamentación radical de la libertad que:

“(...) sólo a partir de los principios de una verdadera filosofía de la naturaleza se puede desarrollar esa concepción que satisface por completo la tarea que aquí nos ocupa."6

Aún cuando pueda criticarse una caracterización como la propuesta por Hegel en sus Lecciones sobre la historia de la filosofía ${ }^{7}$, donde dice ser el idealismo depurado tanto de Fichte como de Schelling, está claro que dentro de su doctrina ambas posturas mentadas no hallarían una verdadera fundamentación de la libertad y seguirían mostrando una conciencia servil. Pues bien, conciencia servil, pero ¿respecto a qué? En una carta fechada en 1795 Hölderlin le detalla a Hegel refiriéndose a Fichte:

"Su Yo absoluto (=Sustancia de Spinoza) encierra toda la realidad. Es todo y fuera de él no hay nada. Por tanto, este Yo absoluto no tiene objeto; de otro modo, no encerraría toda la realidad. Pero una conciencia sin objeto es impensable; incluso si yo mismo soy ese objeto, en cuanto tal me hallo necesariamente limitado, aunque sea en el tiempo; por tanto, no soy absoluto. De modo que una conciencia es impensable en el Yo absoluto, como Yo absoluto no tengo conciencia, y, en tanto en cuanto no tengo conciencia, soy nada (para mí) y el Yo absoluto es (para mí) Nada"8.

Pues bien, se trata de un gesto complicado. $Y$ es que Hölderlin le hace efectiva a Hegel una crítica a Fichte, diciendo que le suena a dogmático, de la que se servirá Hegel pero, por otra parte, hace efectiva indirectamente una referencia al mismo Schelling que, por esos años (1795), se separaba ya de la doctrina fichteana tomando influencias declaradas, como señalamos, de Spinoza. Se puede apreciar entonces que Hegel se servirá de la crítica de Hölderlin pero, a su vez, para usarla contra éste. Puesto que Hölderlin seguirá criticando, como protesta contra los dogmáticos, el intento de sobrepasar los hechos de la conciencia si no es a través de una experiencia de intuición estética. De tal modo, si bien valorando la experiencia de Hölderlin en torno al alejamiento

\footnotetext{
${ }^{5}$ Cfr. G. W. F. HEGEL, Diferencia entre el sistema de filosofía de Fichte y el de Schelling, Madrid: Editorial Tecnos, 1990, p. 139.

${ }^{6}$ F. W. J. SHELLING, Investigaciones filosóficas sobre la esencia de la libertad humana y los objetos con ella relacionados, Barcelona, Editorial Anthropos, 2000, p. 161. Schelling se refiere acá a la tarea de una fundamentación absoluta de la libertad.

${ }^{7}$ Esta caracterización es así criticada por Félix Duque y puede detallarse en su Historia de la filosofía moderna. La era de la crítica, Madrid, Akal, 1998, p. 206.

${ }^{8}$ G. W. F. HEGEL, Escritos de juventud, op. cit., p. 57.
} 
tanto de Kant como de Fichte que hará también suya, a su modo, Schelling, Hegel criticará ${ }^{9}$ el motivo de ese pasaje que pretende vincular la libertad con un fundamento sólo dado a la intuición. En Hölderlin esa conciencia servil, de ser arrastrado o regido por un principio trascendente que nos conduce, para Hegel podría quedar posteriormente caracterizada a través de muchos pasajes y textos, por ejemplo en Timidez, tercera versión del poema Valor poético, cuando señala:

"Pues desde los tiempos que la poesía/ enseñó el recogimiento/ a los hombres divinos, solitaria raza,/ y aún a los mismos dioses/ y al coro de los príncipes,/ nosotros, lenguas de los pueblos,/gozosamente nos mezclamos al gentío/ siempre amigos de todo, abiertos a cada uno; así como nuestro padre, el dios Cielo..." ${ }^{\prime 10}$.

Es, en síntesis, a cierto espíritu del Romanticismo al que Hegel volverá a oponerse, luego de haberlo experimentado, al criticar la estructuración del devenir mediante un principio trascendente o fundamento que detente el orden de lo real o que arrastre a los individuos. El mundo debe derivar necesariamente de un principio o antecedente que no es arbitrario ni accidental. El comienzo para ser absoluto tiene que ser no mediado, lo inmediato mismo. Contra esto, Hegel elaborará la especificidad de su doctrina.

Bajo este panorama, la determinada crítica hegeliana, que tomará cuerpo luego de trabajar en silencio y vivenciar el Romanticismo, afectará tanto al proyecto ético-político de Kant y el idealismo subjetivo de Fichte, separándose de los desplazamientos y tentativas elaboradas por sus amigos y por los movimientos románticos en general. Preguntándose uno la razón del hecho de que Hegel inserte en la gran Lógica de Jena un comentario sobre la ética después de hablar de la mala infinitud o al preguntarse simplemente cómo un infinito puede ser malo, se apreciará el otro rasgo particular de la crítica hegeliana respecto a sus compañeros y que se centra en una crítica al desprecio fichteano de la naturaleza como al normativismo kantiano y que revela por lo tanto su desprendimiento de las alternativas de emancipación ilustrada que hemos analizado sucintamente.

Efectivamente, ese rasgo particular hegeliano, y que volveremos a encontrar luego, es la crítica de la mala infinitud que relaciona la ética con analogía al infinito mentado como progressus ad infinitum o infinito virtual que, consecuentemente, estructura el obrar práctico como acercamiento infinito a la norma moral externa y absoluta. De ahí que este infinito sea "malo" ya que mienta la ética de acuerdo a una escisión externa, cuestión que prosigue cierto Romanticismo, que Hegel caracterizará como cultura de la nostalgia, que no supera las antinomias ilustradas, como veremos. Aun así, el remedio está, para Hegel, en la misma fuente de la llustración, ya que el mismo Spinoza había mostrado, y geométricamente, el infinitum actu frente a la infinitud fichteana, como detalla Hegel en la Wissenschaft der Logik ${ }^{11}$. Por lo tanto, el que Hegel

\footnotetext{
${ }^{9}$ Posteriormente claro está, pues en un primer momento hará suya la experiencia del poetapensador con términos como amor en torno a una filosofía de la vida.

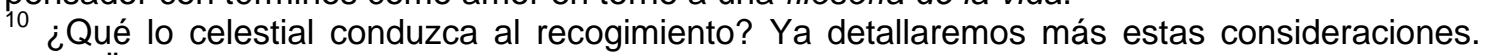
Vid. HÖLDERLIN, Poesía Completa, España: Ediciones 29, Tomo I, p. 83.

${ }^{11}$ Cfr. J. M. Ripalda, op. cit., p. 127. Ripalda señala este aviso de Hegel encontrado en la nota 1 del capítulo "Quantum". Cfr. G. W. F. Hegel, Ciencia de la Lógica, Bs. As., Solar-Hachette, 1968, pp. 181 y 211.
} 
incluya a todos esos movimientos emancipatorios en la misma llustración hace al mismo tiempo destacar que su propuesta no es otra que ilustrar a la Ilustración ${ }^{12}$. Este silencio que hemos querido caracterizar de Hegel es más claro y elocuente aún. Como se sabe, Hegel no se dio ni la molestia de responder la última carta enviada por Schelling, fechada el 2 de noviembre de 1807, donde éste, luego de advertir en el Prólogo de la Fenomenología una referencia explícita a su doctrina de la identidad, le señala:

"(...) confieso no entender hasta ahora el sentido en que tú opones a la intuición el concepto. Tú no puedes designar por este primer término otra cosa sino lo que tú y yo hemos llamado idea, y cuya naturaleza es tener un lado por el cual es concepto y otro por el cual es intuición"13.

Hegel, como vemos, ya ha tomado otro rumbo para intervenir en el desgarrado ánimo epocal.

\section{El dispositivo político de la Fenomenología del espíritu}

La especificidad del proyecto emancipatorio hegeliano debería confrontarse sistemáticamente (como él mismo lo encaró) con los diversos actores y protagonistas de aquellos años (último decenio del siglo XVIII). Cabe destacar entonces que, en ese intento, el de buscar el suelo nutricio que dé cuerpo a una identidad nacional perdida, para Hegel, como vimos, no será solución ni el consuelo de la naturaleza, que buscaban los románticos y el clasicista Hölderlin en momentos, ni el esteticismo redentor schellingiano. El punto cordial de su propuesta, que parece ya señalar su silencio en la correspondencia con los amigos de Tubinga, será el trabajo, arduo, del concepto.

Lo que cabe destacar es el escenario múltiple de actores e intentos de resolución y conducción de las aporías que enfrentaba la llustración. Habría que considerar aquí el intento no sólo de los representantes destacados sino aquellos marginales y desatendidos por los manuales que aportan resoluciones muy interesantes no sólo para la época, como Heinrich von Kleist o Novalis.

Hegel ha señalado casi al final de su periplo intelectual que toda la cultura del momento pertenece al cuerpo de la llustración:

"Aunque ambas partes coincidían en el común interés por la libertad del Espíritu, aquella ilustración, como seco entendimiento de lo finito, perseguía con odio al sentimiento o conciencia del infinito que se encontraba de esta parte, así como su profundidad tanto en la poesía como en la razón"14.

Quedaría por determinar qué intenta Hegel contra esas tentativas y qué mienta específicamente la Ilustración. Lo fundamental acá, como hemos querido señalar, es que todo el conjunto de trayectorias se juega en una suspensión

\footnotetext{
12 Ilustración de la llustración ya mentada en la Fenomenología del espíritu y que puede extenderse al esfuerzo de toda la teoría posthegeliana, muchas veces inconsciente de las figuras y aporías problematizadas por el mismo Hegel. Vid., por ejemplo, Th. Adorno y $\mathrm{M}$. Horkheimer, Dialéctica de la llustración, Madrid, Trotta, 2001, pp. 59 ss.

${ }^{13}$ Carta de Schelling a Hegel, fechada el 2 de noviembre de 1807, parte de la Correspondencia completa, entre Schelling y Hegel, traducción de Raúl Gutiérrez y Hugo R. Ochoa, aún inédita. Más adelante, en otro contexto, se darán más razones del silencio de Hegel.

${ }^{14}$ G. W. HEGEL, Werke, Eds. E. Moldenhauser, K. M. Michel. Frankfurt: Suhrkamp, 1970-1979, t. 11, pp. 277 ss. Citado por J. M. Ripalda, op. cit., p. 126.
} 
política. Lo radical en Hegel será determinar qué tipo de dispositivo puede intervenir mejor y mantener verdaderas relaciones con la efectividad histórica y su devenir. Dejemos preliminarmente suspendidas las palabras de Hegel escritas a Schelling en Frankfurt, en un momento en que confesó haber estado al borde de la locura y que señala el propósito de su traslado a Jena y el rasgo esencial que tendrá luego la Fenomenología del espíritu:

"En mi formación científica, que comenzó por las necesidades más elementales de los hombres, tenía yo que ser empujado hacia la ciencia, y el ideal de la juventud tenía que convertirse, bajo la forma de la reflexión, al mismo tiempo en un sistema; me pregunto ahora, mientras todavía estoy ocupado en ello, de qué modo volver para intervenir en la vida de los hombres" ${ }^{\prime 15}$.

Una revisión de la Fenomenología del espíritu debería dejar en claro, sobre todo para aquellos que se quedaron con el capítulo IV y el análisis del "Señor y siervo"o que intentan hacer de Hegel solamente un precursor adelantado de Marx ${ }^{16}$, que toda la obra está articulada como una tentativa por generar un dispositivo político "efectivamente", esto es, depurando las relaciones aporéticas en que se estrellaba el romanticismo y el clasicismo para fundamentar el accionar histórico de la Nación. La obra está plagada de interlocutores, muchos de ellos tácitos, que dan cuenta no sólo del desgarro de Hegel sino de la múltiple experimentación filosófico-política que realiza su pensamiento. El silencio de Hegel que analizamos en su primera fase es, a este respecto, elocuente. Por otra parte, ese desgarro queda bastante patente si consideramos los fragmentos constitucionales que bosqueja en una época que ha servido para mitificar la figura de un Hegel pietista o filósofo de la vida, sustrayendo todos sus esfuerzos críticos.

Pues bien, Rosenkranz nos ha legado un resumen de la perdida primera introducción de los fragmentos que Hegel redactara para elaborar La constitución Alemana. El desgarro se manifiesta en que en esa primera introducción, escrita en 1798, Hegel se preguntaba cuál podría ser la causa de la decadencia del imperio alemán. Refuta al comienzo Hegel los argumentos que deducían tal decadencia de la falta de valor personal o de la idea de una bancarrota nacional, como de la falta de cultura, eticidad o religiosidad. Hegel señalaba, más bien, que "(...) la causa de la perdición no debe ser buscada en los individuos, sino en el mecanismo del todo"17. Es precisamente ese todo lo que hay que remarcar no sólo para comprender su propuesta global sino para determinar la especificidad del nudo cordial de la tentativa elaborada posteriormente en la Fenomenología. Es el mecanismo del todo lo que no se ha pensado y lo que desgarra la epocalidad mentada, es el mecanismo lo que debe determinarse. Hegel redacta esa introducción en una época en que, como se señaló, creyó volverse loco. Tal locura no es sino el intento de distinguir e instalar un nuevo dispositivo político, que hace experimentar a Hegel todas las categorías en boga, sobre todo las románticas desprendidas del clasicismo-

\footnotetext{
${ }^{15}$ Cursivas mías. Carta de Hegel a Schelling fechada el 2 de noviembre de 1800 en Frankfurt, parte de la Correspondencia completa, entre Schelling y Hegel, traducción de Raúl Gutiérrez y Hugo R. Ochoa, aún inédita. Con esta carta se puede señalar que comienza el nuevo binomio del idealismo, con Schelling y Hegel, en su desprendimiento del idealismo subjetivo fichteano con el que se relacionó tempranamente Schelling.

${ }^{16}$ Cfr. Félix Duque, Historia de la filosofía moderna. La era de la crítica, op. cit., p. 517.

${ }^{17}$ G. W. F. HEGEL, Escritos de juventud, op. cit., p. 387.
} 
ilustrado, pero, a su vez, esa locura es la plataforma del primer intento político desarrollado que será la Fenomenología.

El § 25 la Enciclopedia echa luces sobre el estatuto de la Fenomenología como plataforma del desarrollo que tomará cuerpo cabal en la gran Lógica. Hegel señala ahí respecto a la Fenomenología:

"Para lograr tal cosa no era, sin embargo, posible detenerse en lo formal de la conciencia pura, pues el punto de vista del saber filosófico es al mismo tiempo el más rico y lleno de contenido en sí mismo y el más concreto; así pues, produciéndose como resultado, el saber filosófico presuponía también las figuras concretas de la conciencia, como, por ejemplo, la de la moral, de la eticidad, del arte, de la religión. (...) aquel desarrollo, por así decirlo, ha de suceder a espaldas de la conciencia, por cuanto el contenido se comporta como el en-sí respecto de la conciencia. (...) La consideración preliminar que hacemos aquí tiene más aún la incomodidad de poderse hacer solamente de manera histórica y raciocinante (...)"18.

Hegel aduce dificultades en la exposición del desarrollo de la conciencia expuesto en la obra, ya que los contenidos socio-históricos pueden dificultar la transparencia de la determinación lógica que, dado ese primer paso, cobrará verdadera fuerza en la Ciencia de la lógica donde tienen verdadero puesto las determinaciones conceptuales, necesitadas preliminarmente de contenido.

Es el mosaico de tentativas sociopolíticas lo que mantiene en vilo el pensar hegeliano, su totalidad. Convendría acá finalmente detallar lo que se mienta por llustración en Hegel en esa primera tentativa y comparar algunos rasgos distintivos del dispositivo que intenta posicionar.

Como habíamos señalado, el intento de Hegel será determinar el desgarro histórico en que culminaría la llustración mediante la crítica de la violencia especulativa de la nueva filosofía. La Nación ya no será recuperada ni por la vivencia de la naturaleza ni por la obra de arte. Lo que se va fraguando, desde La constitución alemana es una crítica al normativismo ilustrado y su constitucionalidad que hace del Estado una máquina abstracta que trata a los individuos como engranajes, pero tal crítica, como hemos barruntado, insertará a aquellos que con sus propuestas no hacen otra cosas que acrecentar esa violencia especulativa. Lo que cambiaría respecto a los escritos de Frankfurt y Berna sería esa Volksreligion estetizante emplazada a través de conceptos como vida y amor y reemplazados por otros como muerte y realidad en los escritos de Jena. Se trata de crear una nueva cultura pero no mediante una anti-Ilustración (Gegenaufklärung) sino mediante una llustración de la Ilustración, una Aufklärung über die Aufklärung. En ese intento serán enemigos por antonomasia, o figuras paradigmáticas de combate, por una parte, el ultraracionalismo cientificista y, por otra parte, el fideísmo beato ${ }^{19}$.

${ }^{18}$ G. W. F. HEGEL, Enciclopedia de las ciencias filosóficas, Madrid: Alianza, 1999, p. 132.

${ }_{19}$ Cfr. Félix Duque, La estrella errante. Estudios sobre la apoteosis romántica de la historia, Madrid, Akal, 1997, p. 80. F. Duque resalta ese intento desgarrador de la Fenomenología de una nueva instalación de la Nación dividida en oposición a cierto romanticismo como vía de salida. A su vez, en tal estudio, somete a comparación a este respecto la tentativa de Hegel con la elaborada por Nietzsche en El nacimiento de la tragedia a partir del espíritu de la música. 
Ya se ha introducido entonces un giro de ese panfleto revolucionario temprano de los amigos de Tubinga:

“iPor lo tanto, tenemos que ir más allá del Estado! Porque todo Estado tiene que tratar a los hombres libres como a engranajes mecánicos, y puesto que no debe hacerlo debe dejar de existir"20.

Ya que, a su vez, en tal proyecto, los amigos afirmaban:

"Finalmente, la idea que unifica a todas las otras, la idea de la belleza, tomando la palabra en un sentido platónico superior. Estoy ahora convencido de que el acto supremo de la razón, al abarcar todas las ideas, es un acto estético, y que la verdad y la bondad se ven hermanadas sólo en la belleza"21.

Razones tenemos, como hemos tratado de mostrar, para creer que Hegel se mantenía con cierto recelo al momento de escribir el panfleto. No caben dudas de que compartía el entusiasmo de sus amigos revolucionarios, pero ya se ha notado que la belleza por sí sola no será un dispositivo político adecuado. El problema es ya el mecanismo del todo. Ahora bien, una afirmación semejante en cuanto al diagnóstico de aquel Primer programa de un sistema del idealismo trascendental de los amigos en esa temprana fase, se puede encontrar en los textos del poeta-científico Novalis y su proyecto de un idealismo mágico. Sirva de ejemplo de ese esteticismo mágico redentor uno de sus más famosos poemas:
"Cuando ya ni los números ni esquemas constituyan la clave de los hombres, y aquellos que ahora cantan o besan posean mucha más ciencia que un sabio; cuando a una libre vida vaya el mundo y torne de esta vida hacia sí mismo; cuando la luz y sombra nuevamente en claridad auténtica se unan; y cuando en la poesía y la leyenda se halle la historia auténtica del mundo, entonces una mágica palabra ahuyentará a cualquier falsa criatura"22.

Novalis, como Schleiermacher, prosiguen el proyecto ilustrado de una nueva Volksreligion pero ahora como relevo irracional de tal proyecto. Con Novalis, como en Hölderlin, se hace patente además la confianza escatológica en un Dios por advenir que toma toda su fuerza en un texto ya clásico como La cristiandad o Europa, redactado en 1799, que comparte muchos de los motivos del diagnóstico redentor-estetizante del Programa de los amigos de Tubinga. No obstante, aun cuando debiera analizarse, para una articulación global en torno a la experiencia romántica de Hegel, El espíritu del cristianismo y su

\footnotetext{
${ }^{20}$ Escritos de juventud, op. cit., p. 219.

${ }^{21}$ Ibíd., pp. 219-220.

22 NOVALIS, Himnos a la noche y otros textos, Losada, 1997, p. 40.
} 
destino escrito de igual forma en 1799, un texto ejemplar se puede encontrar contra Novalis para problematizar aún el fideísmo y el cientificismo racionalista como ejes de antagonismo de la tentativa hegeliana. Debieran, como señalamos, articularse los momentos de experimentación romántica de Hegel, no obstante, dados ya estos indicios de su elaboración, confrontaremos la crítica final que desarrolla en $1807^{23}$.

\section{El alma bella}

Luego de este recurso histórico-sistemático sobre la llustración analicemos qué nos señala y a qué nos conduce Hegel en la Fenomenología del espíritu. Quiero detenerme para ello en el análisis del alma bella. La importancia de este texto radica en que no sólo constituye la última figura del espíritu en su encarnación histórica habiendo asumido ya las otras enajenaciones 0 desgarramientos ${ }^{24}$ sino que además revela la disidencia y postura de Hegel respecto a la exaltación y crítica romántica respecto de la Revolución Francesa. Conviene así precisar antes que es a partir del capítulo VI en que comienza a coincidir la conciencia, asumida su espiritualidad, con el devenir de los procesos históricos, reconociendo ya que toda conciencia en el mundo es conciencia del mundo. Hegel ha detallado ya que la llustración se constituye como el marco histórico de lucha entre la intelección (el saber de la cultura, su reconocimiento) y la fe, como saber inmediato. La llustración tendría como tarea modelar históricamente la crítica al pensamiento transmundano del saber inmediato. Ahora bien, Hegel señala que ese saber inmediato debe ser considerado, ya que, de lo contrario, la conciencia se ve alienada por el intento de corregir el ser mediante un deber ser que no ha asumido ese saber inmediato de facto. Esta es la experiencia revolucionaria ${ }^{25}$ (el terror ilustrado se podría decir), que generará un nuevo escenario epocal. Aquí entra en juego la crítica del criticismo kantiano en analogía con la mala infinitud. Dado ese terror posrevolucionario, la conciencia se pliega sobre sí, estableciendo una dicotomía entre la moralidad y el ser, entre el mundo fenoménico y la buena conciencia, que sólo será encauzada mediante los postulados prácticos. Pero tal escisión es en síntesis una nueva figura de enajenación que promulga el obrar como proceso de acercamiento a una ley externa. Es contra esta experiencia que se alzaría una nueva figura que intentará revalidar esa norma absoluta externa en el corazón mismo de la conciencia, no ya como escisión externa. La conciencia del bien ya no será así algo exterior.

Consignemos antes de entrar a este difícil y duro texto de Hegel en torno al alma bella algunas palabras. Como se sabe, la expresión alma bella configura un nudo cordial del romanticismo alemán y sería acuñada por Friedrich Schiller

\footnotetext{
${ }^{23}$ F. Duque señala estas vinculaciones entre Nietzsche-Hegel y la Frühromantik. El texto para la comparación es precisamente la Fenomenología que señalaría cierto compromiso común (como el que hemos analizamos) aunque Hegel, no obstante, explícitamente supera en 1807, respecto al romanticismo temprano de Novalis específicamente, su proyecto histórico-político. Cfr. F. Duque, La estrella errante, op. cit., p. 87.

${ }^{24}$ Alienaciones, si seguimos a G. Lukács, que hace de este concepto el nudo cordial de la Fenomenología hegeliana. Cfr. G. Lukács, El joven Hegel y los problemas de la sociedad capitalista, México: Grijalbo, 1963, pp. 516 ss.

${ }^{25}$ Cfr. El análisis de la ilustración y el terror en Hegel, Fenomenología del espíritu, México: FCE, 1966, pp. 343 ss.
} 
en De la gracia y la dignidad de $1793^{26}$. Con ella el romanticismo criticaría el normativismo ilustrado en uno de sus momentos estructurales, esto es, la escisión entre la ley moral, el deber ser, y la sensibilidad, representando estrictamente tal figura para el romanticismo la moralidad no como imposición jurídica sino como espontaneidad del corazón, que sería el fundamento de la fusión entre entendimiento y sensibilidad como guía del obrar práctico. Como veremos, será con el Hegel de la Fenomenología y no con Nietzsche con quien se empiece a barruntar el trasfondo ético-político que gobierna su establecimiento. Nietzsche, en pasajes ya célebres, se referirá, después de Hegel, al alma bella para caracterizar una moral de esclavos o resentidos que soslayan las condiciones históricas de la vida fáctica ${ }^{27}$. La crítica del martillo de Röcken es bastante similar a la hegeliana, como veremos, donde posiciona al alma bella al fin como égida de la satisfacción desilustrada que no hallaba sitio tras la decadencia política.

La figura tácita que moviliza no obstante el ataque hegeliano en la Fenomenología es, como señalamos, el idealismo mágico de Novalis, como deja entrever su duro final:

"el alma bella, por tanto, como conciencia de esta contradicción en su inconciliada inmediatez, se ve desgarrada hasta la locura y se consume en una nostálgica tuberculosis" 28 .

Novalis, el poeta-ingeniero, alumno de Schiller, que intentó la reunificación de todas las ciencias en la poesía, en quien puede verse con claridad las consecuencias de la radicalización ilustrada pues, como se sabe, en sus poemas, la Noche es la representación de lo absoluto, mientras que la $L u z^{29}$ es el intelecto ilustrado que debe combatirse para acceder de forma plena a su mentada idea del mundo como communio erótico-estética en la que el hombre es el Mesías, refugiado en el misticismo estético ${ }^{30}$. Hegel seguirá el camino inverso del novaliano, desprendiéndose de forma clara de su temprana filosofía de la vida.

¿Qué nos enseña Hegel en tal pasaje? ¿Por qué su selección? Pues bien, debería considerarse, como dijimos, sabiendo que un interlocutor tácito será el idealismo mágico de Novalis, contraponer dos textos. Por una parte, el poema en prosa La Cristiandad o Europa, de 1799, donde se hace manifiesto todo el poder especulativo de Novalis. Por otra parte, un texto de Hegel de igual data como El espíritu del cristianismo, ya que podrían verse ahí no sólo las consonancias filosóficas en torno al cristianismo, obviamente, y al influjo de Novalis y de la experiencia romántica en general, sino, de forma esencial, lo que se mentará por positividad. Hemos preferido agrupar la referencia de

\footnotetext{
${ }^{26}$ Transita esta categoría por toda la Goethezeit. El mismo Goethe la utiliza titulando el sexto capítulo de su Wilhelm Meister "Confesiones de un alma bella".

27 F. NIETZSCHE, Genealogía de la moral, Madrid: Alianza, 1981, I, 10, pp. 42-46. En el Crepúsculo de los ídolos habla respecto al alma bella, a su vez, como de "áureas mediocridades". Confróntese también en La gaya ciencia., “¿Qué es romanticismo?”.

28 G. W. F. HEGEL, Fenomenología del espíritu, op. cit., p. 390. Novalis (o Friedrich von Hardenberg, según su nombre de origen), como se sabe, murió en 1801 a los 29 años de edad de tuberculosis.

29 Puede verse esta tensión en el poema ya citado anteriormente. Téngase en cuenta aquí también la crítica hegeliana a la Noche (que profesaban los oscuros Schelling y Hölderlin) en su poema Eleusis. Hegel, Escritos de juventud, op. cit., pp. 213-215.

${ }^{30}$ Cfr. F. Duque, Historia de la filosofía moderna. La era de la crítica, op. cit., pp. 457-458.
} 
Novalis específicamente con la Fenomenología, ya que se encuentra ahí no sólo la protoforma de la crítica romántica, sino porque lo puesto en discusión es precisamente el estatuto que tendría la Revolución Francesa y el criterio para determinar la efectividad política del pensamiento. En un plexo de elementos que se ponen en juego, sobre todo hay que recalcar que la crítica de Hegel viene después de un detalle de la revolución y el terror, que atañe en su forma histórica a la exaltación romántica, y en su forma lógica a los modos operativos y políticos del romanticismo alemán.

En su poema en prosa, Novalis defenderá, tras una lectura apasionada de Edmund Burke, la Europa cristiana medieval en oposición al protestantismo caracterizado como plataforma del racionalismo ilustrado a combatir. Pues precisamente la reforma sería el quiebre de esa pintura mítica a la que Novalis consagra su nostalgia. En ese esquema integrador, la revolución francesa será el vestigio de la ruina iniciada por la reforma, aún cuando, por ser el extremo de un proyecto sociohistórico global, puede ser plataforma de un nuevo despertar religioso en el que Novalis insta a refugiarse a cada momento:

"Se ilustró sobre todo, preferentemente, al pueblo común, y se le enseño ese cultivado entusiasmo, surgiendo así una nueva corporación europea: los filántropos o ilustradores. Desgraciadamente, la naturaleza siguió siendo maravillosa e inconcebible, poética e infinita, a pesar de todo ahínco que se puso en modernizarla"31.

¿Habrá que esperar ese refugio?, obsérvese el final del texto de Novalis:

“¿Cuándo y cuándo será? No se haga la pregunta. Sólo paciencia, ella vendrá, debe venir la era sagrada de la paz perpetua, en que una nueva Jerusalem será la capital del universo; y, hasta entonces, guardaos serenos y valerosos en los peligros de la época, compañeros de mi fe, proclamad con palabras y con hechos el divino Evangelio, y permaneced fieles a la fe infinita y verdadera, hasta la muerte"32.

Es difícil no ver en tal pasaje un compendio del nihilismo reactivo que alentara críticamente al Hegel de la Fenomenología del espíritu. ¿Puede, realmente, esperarse nostálgicamente una respuesta de tiempos pasados? ¿Y esperarse algo? ¿Apelando al reconocimiento de un vínculo natural perdido? Esta figura es la protoforma de la crítica hegeliana que, en terapia además de sí mismo, hará del desgarro epocal una figura con la que habrá que contar y, por ello, trabajar, hacer de la teoría misma una categoría de intervención ${ }^{33}$. Detallemos entonces un poco más el desarrollo de la crítica hegeliana. Como aducíamos, acá se encuentran más razones para entender el silencio de Hegel a la última carta que le envía Schelling, donde éste señala no comprender lo que mienta Hegel por concepto, ya que Schelling sigue entendiéndolo como parte, junto con la intuición, de la idea que las contendría como polaridades en ella misma.

\footnotetext{
${ }^{31}$ NOVALIS, "La Cristiandad o Europa", traducción, presentación y notas de Pablo Oyarzún, en: Revista Teoría, N. 5-6, Universidad de Chile, Diciembre 1975, p.139.

32 NOVALIS, "La Cristiandad o Europa", op. cit., p.146.

33 Puede servir además como protoforma crítica de cualquier intento por establecer un paraíso perdido o un arkhé del desvelamiento primigenio o en torno a la escatológica venida de un último dios. Hegel además es conciente y analiza diversas formas de evolución de la fe, o el proceso evolutivo de la fe misma, cuestión por completa ignorada por Novalis para quien sólo existía esa fe pintada míticamente a la cual hay que volver.
} 
En fin, ¿qué piensa Hegel del alma bella romántica? ¿Qué piensa de esa nostalgia redentora y esteticista y, a la vez, fideísta? ¿Qué promueven políticamente?

Pues bien, como señalamos, el capítulo VI (específicamente el apartado C. La buena conciencia, el alma bella, el mal y su perdón) ofrecerá la última figura de encarnación efectiva e histórica del espíritu. Corresponde, como se sabe, a la experiencia, ahora propiamente filosófica, del Romanticismo. Por lo que puede considerarse la última parte del recorrido histórico-político de la conciencia antes de entrar en la Religión y su evolución. Tal evolución es analizada por Hegel precisamente porque el resultado de la experiencia romántica será el establecimiento nihilista de una historia sagrada de la que se espera la salvación (escatología patente en Hölderlin y Novalis).

El paso para llegar a esta figura es, de forma sucinta, el siguiente ${ }^{34}$. Hegel ya había señalado, en el capítulo $\mathrm{V}$, que a la conciencia en un primer momento, reconocida ya como conciencia en su mundo, intentará en su resolución y realización disponer del mundo a su placer, pero con ello olvida la sujeción a las leyes (necesidad) antes mentada y que ella ya había interiorizado. Por ello, intentará como segundo momento de la realización, el transformar ese su mundo de acuerdo a la ley del corazón ${ }^{35}$. Pues bien, con ello se revela, trágicamente, que ese mundo es, nuevamente, su propio mundo y, por ello, el proceso de transformación tendrá que interiorizarse a la buena conciencia (ingenua) que pretendía cambiar el curso del mundo de acuerdo a su virtud. De este proceso de la razón alienada, se revela el mundo ético, tratado en el capítulo VI, que nos convoca, ya que la ley que vigila el curso del mundo, contra la escisión externa de la norma absoluta de Kant-Fichte, es ya siempre una figura histórica determinada, contingente. Es el reconocimiento de la historicidad lo que gobierna acá el examen de Hegel, como pasos lógicos encarnados históricamente, y que se repiten, en el reconocimiento de la conciencia desgraciada.

Ahora bien, ya en lo que nos atañe, Hegel coloca a la llustración como la plataforma de lucha entre la intelección y el saber inmediato, la fe ${ }^{36}$. La realización de tal intelección en el mundo es la obra de la Revolución Francesa, con lo que se observa ya un gesto doble de Hegel. Por una parte determinar su validez pero a la vez sus inconsistencias, ya que tal accionar de los ilustrados franceses culmina, como sabemos, en el terror, pero esto necesariamente, ya que en tal intento se supone la libertad absoluta (absuelta) de la razón a imponer, en el reconocimiento a-crítico del factum de ese saber inmediato, o sea, de lo que el mundo "efectivamente" es y está constituido, de ahí que tal

\footnotetext{
${ }^{34}$ Puede detallarse un esquema sucinto del paso dado acá por Hegel a la eticidad en el ya citado texto de F. Duque, La era de la crítica, op. cit., pp. 522-23.

${ }^{35}$ Cfr. Hegel, "La ley del corazón y el desvarío de la infatuación", en Fenomenología del espíritu, op. cit., pp. 217 ss. F. Duque señala que en este pasaje hegeliano hay una referencia tácita a Los bandidos de F. Schiller: La era de la crítica, op. cit., p. 520.

${ }^{36}$ Habría acá que someter a balance la referencia foucaultiana al texto de Kant Was ist Aufklärung? Cuestión que en su análisis nos detendría demasiado cabe destacar que el estatuto del presente que Foucault rescata (su recientismo) para Hegel no estaría desarrollado cabalmente ya que está transido de ideales normativos abstractos, soslayando la experiencia histórica acá mentada. Vid. “¿Qué es la ilustración?" en: Saber y verdad, Ed. La Piqueta, 1986, pp. 197 ss. Y Kant, “¿Qué es la ilustración?" en: Filosofía de la historia, FCE, 2004, pp. 25 ss.
} 
experiencia revolucionaría haga acopio nuevamente de la escisión entre ser y deber ser.

En este momento, ya en la moralidad, se pretenderá en un primer momento ser absolutamente libre nuevamente, pero con ello se escinde otra vez el mundo fenoménico del mundo interior moral y en la que se intentará, ad infinitum, acercarse al ideal de la norma moral absoluta, como en Fichte ${ }^{37}$. Un segundo momento surgirá como consecuencia del anterior, en el cual la conciencia se repliega sobre sí misma, reconociendo entonces la moral no como la imposición de una ley externa sino como interioridad espontánea del sentimiento. Esta constituye la última figura del espíritu, y se trata efectivamente de la experiencia romántica. Tal pasaje, su interpretación por Hegel, nos debería detener en ese refugio novaliano que analizamos y en la experiencia de una verdadera efectividad política.

Esta última figura, después de analizada la llustración, se sustrae en sí misma. Hegel ya ha analizado los distintos momentos de este sí mismo ${ }^{38}$; ahora este sí mismo llena la vacuidad del deber ser absoluto (que al cabo negaba la libertad, reconocida sólo como postulado de la razón práctica) con toda la carga histórica de su pasado que siente como propio. Se sabe ya conciencia moral pero en la inmediata certeza de su sentir moral. Nótese como comienza el texto hegeliano del alma bella:

“(...) en la majestad de su altura por encima de la ley determinada y de todo contenido del deber, la buena conciencia pone en su saber y en su querer el contenido (...)"39.

Se ha llenado ya la vacuidad de la norma exterior pero con el recurso a su sentir absolutamente presente a sí mismo, continúa Hegel:

"(...) es la genialidad moral que sabe la voz interior de su saber inmediato como voz divina y que, al saber en este saber no menos inmediatamente el ser allí, es la divina fuerza creadora que tiene en su concepto la vitalidad" 40 .

El alma bella se refugia así, en la inmediatez de su saber moral, en la voz propia sentida como divina, como influjo divino. El texto, si podemos ya evaluar, es durísimo, como se aprecia en lo que prosigue Hegel:

"El espíritu y la sustancia de su conexión, es por lo tanto, la mutua aseveración de su escrupulosidad y de sus buenas intenciones, el alegrarse de esta recíproca pureza y el deleitarse con la esplendidez del saber y el enunciar, del mantener y cuidar tanta excelencia"41.

Hegel ya había detallado la fundamentación intersubjetiva del lenguaje, como un ser para otro en el mismo sí mismo autoconsciente de su obrar moral a través de él, el discurso. Acá, el alma bella, sólo puede, refugiándose en la inmediatez de su sentir, comunicar y exhortar su sentimiento de plenitud que lo desborda. Mostrar su grandeza moral exhortando a la interioridad del sentir inmediato. Manifestando la comunión mediante ese refugio interior que purga

\footnotetext{
${ }^{37}$ Cfr. "El mundo moral, como representación" en Fenomenología del espíritu, op. cit., pp. 358 ss.

${ }^{38}$ Cfr. Hegel, Fenomenología del espíritu, op. cit., pp. 370.

${ }^{39}$ HEGEL, Fenomenología del espíritu, op. cit., p. 382, algo modificada.

${ }^{40} \mathrm{Id}$.

${ }^{41}$ Id.
} 
los pecados. Hegel acomete su proyecto, esto es lo radical, como crítica de la única oferta de accionar político que se ofrecía a la llustración insatisfecha. Pero con el alma bella, ese accionar es más bien ausencia de obrar, pues tiene su vida "recóndita en Dios" del que espera todo en su escatológico plan divino.

Permítaseme citar un pasaje ahora más largo:

"(...) sabe por tanto su sí mismo como el en sí vivo, y este su saber como la religión, que, como saber intuido o existente, es el lenguaje de la comunidad acerca de su espíritu.

Vemos, así, cómo la autoconciencia ha retornado ahora a su refugio más intimo, ante el que desaparece toda exterioridad como tal, a la intuición del yo=yo, donde este yo es toda esencialidad y toda existencia"42.

Como se aprecia, el callejón al que conduce el alma bella es otra vez una vuelta no mediada al idealismo fichteano que quería depurar, pues si bien ha llenado de contenido su normatividad sigue viendo ese contenido como su sentir interior, lo que hace afirmar a Hegel que ella, su mismidad, es al fin, ausencia de sí mismo, del sí mismo como relación mediadora. Tal es el otro pasaje que ofrece la llustración. Detengámonos un poco antes de ver la salida de Hegel.

Habría que comparar exhaustivamente esos textos hegelianos con La Cristiandad o Europa. Ahí, se llena ese contenido con el cristianismo del medioevo y la esperanza mesiánica en un nuevo establecimiento de lo único que se le ofrece al pensar, la religión, que Hegel analizará inmediatamente después en la Fenomenología, por lo mismo. Pues Novalis quiere establecer:

"Una gran era de reconciliación, un salvador que como genio verdadero habitará entre los hombres, en el cual solamente se creerá, sin verlo, pero que será visible a los creyentes bajo formas innumerables (...),43

Es la manifestación absoluta del desfallecimiento, como deja entrever Hegel elocuentemente:

"(...) esta absoluta certeza en que se ha disuelto la sustancia es la absoluta no verdad que se derrumba en sí misma; es la absoluta autoconciencia en la que se hunde la conciencia"44.

Obsérvense las palabras de Novalis: ese dios será recibido "como la muerte entre los dolores supremos del amor en la intimidad del cuerpo en agonía" ${ }^{45}$. Pero siguiendo a Hegel, debería ser conciente tal mesianismo redentor que:

"este mundo creado es su discurso, que ha escuchado también de un modo inmediato y del que solamente retorna a ella el eco...le falta la fuerza de la enajenación, la fuerza de convertirse en cosa y de soportar el ser. Vive en la angustia de manchar la gloria de su interior con la acción y la existencia; y, para conservar la pureza de su corazón, rehuye todo contacto con la realidad y permanece en la obstinada impotencia de renunciar al propio sí mismo llevado

\footnotetext{
42 Ibíd., p. 383.

${ }^{43}$ NOVALIS, "La cristiandad o Europa", op. cit., p. 142.

${ }^{44}$ HEGEL, Fenomenología del espíritu, op. cit., p. 383.

45 NOVALIS, "La cristiandad o Europa", op. cit., p. 142.
} 
hasta el extremo de la última abstracción y de darse sustancialidad y transformar su pensamiento en ser y confiarse a la diferencia absoluta" ${ }^{46}$.

Hegel ha sido ya claro, no podemos esperar nada si no es con la laboriosidad del trabajo, interventivo, del concepto en su relación mediadora. Esa figura última queda entonces elocuentemente descrita como el carácter del esteticismo escatológico como manifestación de la nietzscheana moral de esclavos o resentidos que no se arrojan a la vida fáctica y su devenir. Consumación última entonces de la resignación nihilista:

"(...) su obrar es el anhelar que no hace otra cosa que perderse en su hacerse objeto carente de esencia y que, recayendo en sí mismo más allá de esta perdida, se encuentra solamente como perdido; -en esta pureza transparente de sus momentos, un alma bella desventurada, como se la suele llamar, arde consumiéndose en sí misma y se evapora como una nube informa que se disuelve en el aire" 47 .

\section{Conclusión}

A través de esta breve meditación hemos querido destacar a lo menos tres cosas. Por una parte, el intento hegeliano se estructura ya desde los escritos de Frankfurt como una tentativa política en que se sospecha del esteticismo como salida de las aporías ilustradas. Por otra parte, su intento está en la instalación de una nueva simbología nacional alejada del mesianismo escatológico de la experiencia romántica, que tras la decadencia exhortaba a la interioridad como refugio moral. Finalmente, como hemos apreciado, la obra está llena de interlocutores, con lo que haciendo efectivo un compromiso con su presente, intenta mostrar críticamente el desgarro epocal a causa de la resignación nihilista. Novalis, tras el desgarro político alemán, volvería a refugiarse en la interioridad del alma y en el intuicionismo estético relacionando no mediatamente ese, su discurso, con el saber inmediato de la fe y el anhelo. Hegel esboza ya con él y con el romanticismo una clausura epocal que revela el detalle y análisis de sus posiciones frente a la objetividad como el intento de establecer una verdadera efectividad política del pensamiento ${ }^{48}$.

Esa exaltación romántica se consume en el puro sentir de su interior certeza de sí, en analogía al hálito divino. Su solución, al determinarse según Hegel como la contradicción de su sí mismo con la realidad fáctica y el devenir histórico, es aceptar el mal y reconocer su superación a través de la comunión religiosa. Ya que puede ensuciar sus ideales se clausura en su propia subjetividad que, en ese mismo momento, ya no existe, sino para una Historia sagrada de la que únicamente se puede anhelar.

Hegel dedicará un escaso y nuevamente duro párrafo a la experiencia de la subjetividad novaliana en sus Lecciones sobre la historia de la filosofía, donde señala:

"La subjetividad consiste en la ausencia de algo fijo, pero en la forma de impulso en esta dirección, conservando de este modo su carácter de anhelo.

\footnotetext{
${ }^{46}$ HEGEL, Fenomenología del espíritu, op. cit., p. 384.

${ }^{47}$ Id.

${ }^{48}$ Cfr. HEGEL, Enciclopedia de las ciencias filosóficas, op. cit., pp. 133 ss.
} 
(...) Esta subjetividad...se esfuma dentro de sí (...) es una vida interior y la prolijidad de toda verdad. La extravagancia de la subjetividad se convierte frecuentemente en demencia (...)"49

Ese refugio otorga finalmente a la conciencia moral todas las excusas de su no obrar, que por lo demás no le resulta difícil, pues, simplemente, como señala Hegel: "No le resulta difícil mantenerse en la pureza, pues no actúa"50. Tal es la resignación que moviliza críticamente a Hegel. Si algo se ha aprendido de esta orientación ilustrada es reconocer la mediación histórica y trabajarla. De ahí que su tentativa sea, por el contrario, la laboriosidad del concepto, su instalación en la efectividad de lo real y el reconocimiento de su encarnación histórica, contingente. Por ello Hegel realiza todos esos múltiples agenciamientos, ya que se ha puesto en juego el desarrollo efectivo de una subjetividad mediada por todos esos compromisos, y que revela al fin el desgarro de la subjetividad como desgarro de su inmanencia en el obrar. Si queremos, siguiendo a Hegel, que la subjetividad no se esfume volátilmente, habrá entonces que transitar y experimentar todos esos discursos históricos, todas esas mediaciones, reconociendo ese desgarro.

Nos queda, por sobre ese vano anhelo, el trabajo permanente del pensamiento y su realización histórica. Pues preludio de esa nostálgica tuberculosis será ese anhelo que para Hegel es al fin conciencia servil de una interioridad que vive en la ilusión de su soliloquio con dios en el refugio de su sí mismo absuelto, el alma bella:

"El alma bella carente de realidad, en la contradicción de su puro sí mismo y de la necesidad del mismo enajenarse en el ser y de trocarse en realidad, en la inmediatez de esta oposición retenida (...)"

Hegel, como hemos analizado, nos enseña a dar ese paso en la efectividad de la mediación histórica, de esa enajenación infinita, en cuanto se es para otro, y donde ya no hay refugio ni anhelo.

\footnotetext{
${ }^{49}$ HEGEL, Lecciones sobre la historia de la filosofía, México: FCE, 1997, Tomo III, pp. 484-485.

${ }^{50}$ HEGEL, Fenomenología del espíritu, op. cit., p. 387.

${ }^{51}$ Ibíd., p. 390.
} 


\section{Referencias Bibliográficas:}

HEGEL, G. W. F.: Escritos de juventud. Trad. J. M. Ripalda, Z. Szankay, Madrid: FCE, 1978.

-Diferencia entre el sistema de filosofía de Fichte y el de Schelling, Madrid: Editorial Tecnos, 1990.

-Fenomenología del espíritu. Trad. W. Roces, México:FCE, 1966.

-Ciencia de la Lógica, Bs. As.: Solar-Hachette, 1968.

-Enciclopedia de las ciencias filosóficas, Madrid: Alianza, 1999.

-Lecciones sobre la historia de la filosofía, Tomo III, México: FCE, 1997.

FICHTE, J. G.: Doctrina de la ciencia, Madrid: Akal, 1999.

SHELLING, F. W. J.: Investigaciones filosóficas sobre la esencia de la libertad humana y los objetos con ella relacionados, Barcelona: Editorial Anthropos, 2000.

SCHELLING-HEGEL: Correspondencia completa, traducción de Raúl Gutiérrez y Hugo R. Ochoa, aún inédita.

HÖLDERLIN, F.: Poesía Completa, España: Ediciones 29, Tomo I.

NOVALIS: La Cristiandad o Europa. Traducción, presentación y notas de Pablo Oyarzún, en: Revista Teoría, N. 5-6, Universidad de Chile, Dic. 1975.

KANT, E.: “¿Qué es la ilustración?” en: Filosofía de la historia, México: FCE, 2004.

NIETZSCHE, F.: Genealogía de la moral, Madrid: Alianza, 1981.

DUQUE, F.: Historia de la filosofía moderna. La era de la crítica, Madrid, Akal, 1998.

- La estrella errante. Estudios sobre la apoteosis romántica de la historia, Madrid, Akal, 1997.

RIPALDA, J. M.: Fin del clasicismo. A vueltas con Hegel, Madrid, Trotta, 1992.

LUKÁCS, G.: El joven Hegel y los problemas de la sociedad capitalista, México: Grijalbo, 1963.

FOUCAULT, M.: “¿Qué es la ilustración?”, en: Saber y verdad, Ed. La Piqueta, 1986. 